\title{
From General English to EST: A Proposal to Reform China's Service English Teaching
}

Zhou Zhijian

\footnotetext{
This paper gives a brief survey of service English teaching in China and proposes reform based on the theory and practice of the ESP/EST approach. The survey describes the course materials, classroom teaching activities, and students' reactions to them under the General English approach now prevalent in China, while at the same time noting an apparent upsurge of interest in EST among Chinese learners and teachers of English. The proposal
}

argues for a shift from General English to EST and offers solutions to such problems as the preparation of EST course materials, the training of EST teachers, and the testing of EST learners. The paper also reveals how expatriate teachers of English working in China could assist in the reform and why textbooks produced in the U.S. and Britain do not suit Chinese students of science and engineering very well.

In recent years there has been an upsurge of interest in English for Science and Technology (EST) in China. The term "EST" has become so appealing that college students and post-graduate technicians who wish to further their specialized studies through English are quick to buy any book that contains such terms as "Scientific English" or "English for Science and Technology," in its title. In many technical institutions of higher learning, service English departments have set up their own teacher-preparation programmes under the name of EST, in the hope that they will be able to supply themselves with trained service English teachers. Even in universities and foreign language institutes, where English language and literature teaching was regarded as more respectable than the teaching of service English, there have also appeared more practically-oriented programmes, designed to produce interpreters or translators better qualified than ordinary English department graduates for jobs in such professions as law, international trade, journalism, and business management. In service English teaching, the commonplace slogan of "all-round development of the four skills" has given way to a more realistic strategy of placing greater emphasis on the development of reading skills, especially those skills which make it possible to read more quickly.

All of these developments reflect an increasing awareness of the importance of English as a tool which can facilitate access to modern scientific and technological advances and they mark a trend away from the nebulous 
concept of General English toward a closer examination of the needs of the learner.

\section{Persistence of General English Teaching}

If we look at the other side of the picture, however, we will note the persistence of conventional General English teaching. An examination of the current course materials, classroom activities and students' reactions to them will reveal this persistence.

\section{Course Materials}

Although it is widely held that service English instruction should aim at developing non-English majors' ability to use English, to receive and (to a lesser degree) to convey information associated with their specialized studies, no textbooks have been specially designed for this purpose. Those textbooks that are available for science and engineering students now are either variations of China-produced "Essential English" or general EFL materials produced abroad. The former are essentially accelerated versions of the secondary school syllabus, with an emphasis on the teaching of grammatical structures and lexical items, though they do contain some science- or technology-oriented texts. Where American or British materials are used, problems arise mainly from the possibility of irrelevant subject matter and vocabulary.

\section{Teaching Activities}

In theory, every Chinese teacher of English knows that science students should be enabled first to read academic publications in English in their chosen field and in the later stage to write research papers or to understand lectures related to their major when they work for advanced degrees in English-speaking countries. In practice, however, most teachers make no attempt to help their students realize these goals. Such helpful skills as recognizing relations between parts of a text through lexical cohesion devices, oral reporting, and notetaking are usually ignored. Instead, class sessions are still dominated by such activities as identification of parts of speech and sentence elements, reading aloud, substitution drills, listening comprehension based on taped passages, and translation exercises. There are almost no opportunities for students to use English to state their own opinions as specialists, to communicate new information to others, or to write something of specialized interest. Consequently, at the end of an English programme students often find themselves unable to follow a reading passage, or to use their limited knowledge of English to further their specialized studies. 


\section{Students' Reactions}

As a result of the type of instruction described above, most science and engineering students feel somewhat sceptical of their capacity to learn the English language. This is especially evident in their attitude toward vocabulary learning. One can frequently hear non-English majors complain: "There are so many words to learn. I simply can't remember them. I must have forgotten ten times more words that I have committed to memory." "Those reading materials are full of words I don't know. How can I read them faster?"

Reactions to grammar-centred instruction vary from student to student. The majority feel embarrassed by the complicated grammatical rules governing the usage of words; others simply find it boring to sit in a grammar class. Of course, there are quite a number of students who show interest in grammar, but they are mostly beginners and those who would like to try their hand at translating a text of moderate difficulty. These students often become suddenly disillusioned with grammar when they find themselves totally unable to express their ideas in a context of meaningful communication.

\section{The Ill-Defined "Essentials"}

From the foregoing, it is clear that most science and engineering students do not welcome General English instruction. Even so, many teachers still urge their colleagues to remember the usefulness of General English. They argue: the aim of General English is to equip learners with its most essential elements-the basic word stock and grammatical rules, or the common core of the English language. Once a science student or any other non-English major has grasped these essentials, he will readily become a good digester of the literature in his specialized field, since at that time he only has to cope with the technical terms, which should pose no problem to him at all if he has a technical dictionary at hand; and if postgraduate practice continues, he should not find it too difficult to put his "special purpose English" to use.

But we need to face the undeniable fact that at the end of a regular four-year programme, many "English majors fail to get the gist of a text;" "they read at a low speed and are still inept at using the language." (Wang and Youfong 1984:11-15) This being the case with English majors, how much can we expect from non-English majors, who usually have only a maximum of four semesters of English instruction?

In addition, there is a time factor we must consider: how long does it take to gain a good knowledge of these essentials, essentials that seem to defy precise specification? Without specification of the scope of its use and the target level for the learner's command, "common core English" 
is such a vague idea that it cannot even be used to distinguish the beginner from the advanced learner of the language. According to Diller (1971:1), "Roman Jakobson likes to tell the story of how Professor Antoine Meillet of Paris University and Professor Edgar Sturtevent of Yale, two of the world's great Indo-European linguists of the last generation, had to talk to each other through an interpreter when they met." But we cannot say that these two professors had no knowledge of "the essentials." This anecdote shows that a good knowledge of "the essentials" will not necessarily lead to the attainment of communicative competence. This being the case, when will our non-English majors be able to use the English of their specialized field if they are required to grasp "common core English" first?

We also have to consider the feelings of students. Most science and engineering students in universities in China have had some years of General English instruction and have a grounding, even though inadequate, in "common core" English. General English at the university level to them would inevitably mean re-learning material of which they already have some knowledge. This repetition of content and techniques would, of course, be appealing were it presented in association with the students' specialized knowledge, for that would provide some new elements for the students to learn. But this can hardly occur within the framework of General English teaching. And lack of newness inevitably leads to boredom.

\section{New Approaches}

Sensing the inherent weaknesses of the General English approach, many service English teachers tried to find a way out.

The first trial of this kind was to use Chinese-produced discipline-based English textbooks for specialized students. Such textbooks, though closely associated with the technical purpose of the students, use a format that does not lend itself to the instruction of the language functions the students are expected to be able to handle. Each lesson begins with a section entitled Pattern Drills which consists of five or six sentence patterns intended for the students to drill and remember. A short passage follows under the heading Text. Though related in content to the students' speciality, it is often abridged or rewritten in order to keep the grammatical structures in the text within the limit as intended in the Pattern Drills section. Next, a section entitled New Words and Expressions provides Chinese glosses and phonetic transcriptions of vocabulary items in the previous two sections. Then a section entitled Grammar describes in Chinese the grammatical teaching point for the lesson. Finally, a set of exercises focusses on the grammar taught in the lesson. This approach, as we have seen, resulted in the students' poor command of English in both oral and written communication for meaningful purposes. 
The second kind of trial in this direction, which is now going on at some institutions of higher learning in China, is to use British or American textbooks that cover a broad spectrum of topics of general scientific and social interest. Although the general science content shows a certain degree of relevance to the students' needs, they aim at developing the full range of language and study skills: reading, writing, listening comprehension and speaking, with a vocabulary of about 6,000 words. Such books might produce good results provided there are enough qualified teachers to use them as directed, enough language lab capacity for the number of students attending audio-visual sessions at the same time, and particularly enough class hours per week that may be assigned to the study of English by non-English majors. As few institutions in China have the resources to meet all these requirements, such text books seem to have set too high an aim for science and engineering students in China, although they are good books from the point of view of methodology.

\section{What is EST?}

If, as shown above, General English is irrelevant and the new approaches show no great promise, then an examination of what ESP/EST is may provide us with some guidance on what we should do.

EST, as is now widely acknowledged, is a major sub-division of the field of teaching English for Specific Purposes (ESP). It focusses attention on the needs of the learner, needs that may be specified in terms of "the precise area of language required, skills needed, and the range of functions to which language is to be put," (Mackay and Mountford 1978:4) in the fields of science and technology. It is concerned with teaching English as a tool, not as an end in itself. Its significance lies in its attempt to achieve the required level of linguistic and communicative competence in the minimal amount of time.

With such an understanding of EST in mind, a service English teacher, when commissioned to take a class of college students of, say, physics, and authorized to act as he sees fit, will probably tackle the task in the following way:

1) Because our service English teacher can assume that the students have received a grounding in Basic English at the secondary school level, he can proceed directly to EST at the university level. He will first try to gather the necessary information about the students and their communication needs either by a questionnaire or by means of a structured interview with the students (Mackay 1978:21).

2) Based on the information gathered concerning the students' discipline, specialization, and other areas of study, he will move on to specify the area and complexity of English his students are required to handle 
and the flexibility of communication expected of them. This information, in turn, guides his subsequent choices as to the functions to which English will be put, such as stating information, making hypotheses, giving justifications, explanations, and definitions, and drawing conclusions, as well as the skills needed, such as understanding relations between parts of a text through lexical cohesion devices, interpreting a text by going outside it, identifying the main points in a piece of discourse, compressing sentences or word groups, and transcoding information presented in a diagrammatic display into speech or writing (Munby 1978:123-132).

3) With syllabus specifications as described above and with information gathered about the students' present level of English proficiency and scientific knowledge, our teacher will start composing texts on topics associated with their specialized area of study. For those students who are still slow at distinguishing word forms or find it hard to get the gist of most of the sentences in a passage, some sort of instruction for beginners and pre-intermediate students is necessary. For those who prove to be able to link words to their knowledge of pronunciation, grammar, and semantics, and to their scientific knowledge as well, American or British science textbooks or technical journals related to the students' specialized subjects may be used. Incorporated with carefully designed exercises that show an equal concern with the linguistic and communicative properties of the English language, the materials so derived are finally organized into units and arranged in such a way as to ensure that the students will effectively learn the notions, functions, and language and study skills specified in the syllabus. At this point, our EST teacher has arrived at an English course that bridges the gap between the present and target levels of the students' English competence.

4) He presents the material in such a way as to accommodate the learning ability of his students and to help them develop a knowledge of how sentences are used in the performance of the required communicative functions, such as definition, classification, process description, transcoding, and notetaking, as well as of how sentences are formed as sequences of technical and semi-technical words joined together through careful use of such structural words as determiners, conjunctions, prepositions, and various sub-classes of pronouns. That is to say, his teaching method also marks a shift of attention from mere usages of English to both usages and uses of English.

\section{Strengths of the EST Approach}

As can be seen from the above, the content of an EST course is characterized by the inclusion of carefully selected vocabulary, grammatical pat- 
terns, themes, skills, and communicative knowledge of English. This clear specification of what is to be taught will ensure: 1) There will be fewer pitfalls for the student than we saw in General English, because obscure and irrelevant words and expressions are avoided; 2) The teacher will teach as the student's needs direct him, not as his personal interest would drive him, which is often the case with a General English teacher; 3) The student will feel drawn into using English to express what he actually wants to say, since both the themes and the needed linguistic means he learns in the classroom match his own interests; and 4) As a result of the above, the student will likely learn English with far greater ease and far less frustration than under the General English approach.

To the advocates of a broad education for university students, however, this approach would simply mean a limiting of exposure to a general culture and a narrowing-down of students' adaptability. In reply to this opposing view, we would like to say the following: 1) Where there is a great demand on the students' time for their specialized studies, talk of general cultural education through a foreign language would be extravagant. 2) Deep reading in scientific topics, as in any other kind of topics, will provide exposure to a tremendous amount of syntax and vocabulary that is also used in other domains. A high level of reading facility in one specialized field will certainly facilitate learning to read in another field when it becomes necessary for the student to do so after the course. 3) For those who have time for subjects other than their specialized studies, a flexible liberal education may be provided in such extra-curricular activities as public lectures, extensive reading workshops, literature societies, and video-viewing gatherings.

\section{Problems to be Solved}

There are several problems to be solved if we are to apply the ESP/EST approach to China's service English teaching.

\section{Teaching Material Preparation}

The biggest problem is that China has not yet produced enough teachers capable of undertaking to prepare authentic, content-related English reading materials. This difficulty is compounded by the fact that even in English-speaking countries "there are not enough suitable ESP materials." (Strevens 1985:5). This, however, could not be an insurmountable obstacle to the introduction of EST to China's higher education if it is truly worth trying. We may proceed in a tentative manner by aiming at the outset only to prepare such teaching materials as are needed by those undergraduates whose purpose for learning English is restricted to reading technical journals in their specialized fields; such materials can be taken, through selec- 
tion with the help of the content specialist, from content-related textbooks and technical journals aimed at native speakers of English. In compiling such materials, assistance from English teaching specialists is necessary and expatriate teachers working in China could play a very important role.

\section{Testing}

As testing is not a normal communicative activity, some proponents of ESP/EST claim that testing is inappropriate; some hold that only informal tests are needed. Taking China's present situation into consideration, we deem it possible and necessary to administer some form of formal tests if the aim of the tests is to assess the achievement of the Munbyan microskills (Munby 1978: 116-132) pre-selected in the course material, as well as of the main linguistic elements needed in deploying those skills. The format may be either conventional or it may require the students to manufacture some products by consulting written instructions, or to write or translate an article associated with their specialized subjects.

\section{Teacher Training}

In China, few teachers engaged in service English programmes have received training in ESP/EST. Most teachers either lack confidence in presenting science-oriented teaching materials, or they tend to treat scientific texts as they would literary ones. This situation makes it practically impossible to develop real EST programmes. To meet the urgent need for trained EST teachers, two types of EST teacher-preparation programmes might have to be administered: 1) "conversion" programmes directed toward providing in-service teachers with some knowledge of EST theory and practice and changing their attitude toward science and technology; 2) regular graduate-level EST teacher-preparation programmes in which courses such as Applied Linguistics, ESP/EST Theory and Practice, Communicative Syllabus Design, Discourse Analysis, and the Communicative Approach are given the greatest attention and, if possible, one or two basic scientific courses are included. The former may be offered at the several in-service English teacher training centers now in existence; and the latter at some of the country's key polytechnic universities.

Of these three problems, the training of EST teachers is the most crucial. Once there are qualified EST teachers to start real EST programmes and prove that the ESP approach can be truly more successful and more costeffective, it is likely that EST will become dominant in China's English Education. 


\section{REFERENCES}

Diller, K. C. (1971). The Language Teaching Controversy. Rowley: Newbury House Publishers, Inc.

Mackay, R., (1978). Identifying the Nature of the Learner's Needs. In English for Specific Purposes. Ed. Ronald Mackay and Alan Mountford. London: Longman Group Limited. 21-37.

Mackay, R. and A.J. Mountford, (1978). The Teaching of English for Special Purposes: Theory and Practice. In English for Specific Purposes. Ed. Ronald Mackay and Alan Mountford. London: Longman Group Limited.

Munby, John, (1978). Communicative Syllabus Design. Cambridge: Cambridge University Press.

Strevens, Peter, (1985). Two Lectures on ESP: EST after Twenty Years and the Learner and the Teacher of ESP. (n.p.: n.p., n.d.)

Wang, Zongyan and Zhong Youtong, (1984). Stick to the Basics. Foreign Languages (Shanghai), December 1984.

\section{THE AUTHOR}

Zhou Zhijian, professor of English at Huazhong University of Science and Technology, Wuhan, PRC, is the former Vice-Chairman of the Chinese National Association for Service English Teaching, and the designer and coordinator of China's first graduate programmes in EST teacher preparation. He has also written books and articles on English grammar, semantics, and methodology. 